Fixed Point Theory, 19(2018), No. 1, 225-234

DOI 10.24193/fpt-ro.2018.1.18

http://www.math.ubbcluj.ro/ nodeacj/sfptcj.html

\title{
EXISTENCE OF SOLUTIONS TO AN IMPULSIVE DIRICHLET BOUNDARY VALUE PROBLEM
}

\author{
JOHN R. GRAEF* ${ }^{*}$ SHAPOUR HEIDARKHANI** AND LINGJU KONG*** \\ * Department of Mathematics, University of Tennessee at Chattanooga \\ Chattanooga, TN 37403, USA \\ E-mail: John-Graef@utc.edu \\ **Department of Mathematics, Faculty of Sciences, Razi University \\ Kermanshah 67149, Iran \\ E-mail: s.heidarkhani@razi.ac.ir \\ ***Department of Mathematics, University of Tennessee at Chattanooga \\ Chattanooga, TN 37403, USA \\ E-mail: Lingju-Kong@utc.edu
}

\begin{abstract}
In this paper, the authors establish the existence of nontrivial classical solutions for a class of Dirichlet boundary value problems with impulsive effects. The approach is based on variational methods and critical point theory.

Key Words and Phrases: Nontrivial solution, Dirichlet boundary value problem, impulsive effects, critical point theory, variational methods.

2010 Mathematics Subject Classification: 34B37, 34B15, 47J10.
\end{abstract}

\section{REFERENCES}

[1] R.P. Agarwal, D. O'Regan, Multiple nonnegative solutions for second order impulsive differential equations, Appl. Math. Comput., 114(2000), 51-59.

[2] M.S. Alwan, X. Liu, W. Xie, Existence, continuation, and uniqueness problems of stochastic impulsive systems with time delay, J. Franklin Inst., 347(2010), 1317-1333.

[3] L. Bai, B. Dai, Application of variational method to a class of Dirichlet boundary value problems with impulsive effects, J. Franklin Inst., 348(2011), 2607-2624.

[4] L. Bai, B. Dai, Existence and multiplicity of solutions for impulsive boundary value problem with a parameter via critical point theory, Math. Comput. Modelling, 53(2011), 1844-1855.

[5] L. Bai, B. Dai, Three solutions for a p-Laplacian boundary value problem with impulsive effects, Appl. Math. Comput., 217(2011), 9895-9904.

[6] M. Benchohra, J. Henderson, S. Ntouyas, Theory of Impulsive Differential Equations, Contemporary Mathematics and Its Applications, Vol. 2, Hindawi, New York, 2006.

[7] G. Bonanno, A critical point theorem via the Ekeland variational principle, Nonlinear Anal., 75(2012), 2992-3007.

[8] G. Bonanno, B. Di Bella, J. Henderson, Existence of solutions to second-order boundary-value problems with small perturbations of impulses, Electron. J. Differ. Eq., 2013(2013), no. 126, $1-14$. 
[9] G. D'Aguì, Multiplicity results for nonlinear mixed boundary value problem, Boundary Value Problems, 2012, 2012:134, pp 1-12.

[10] M. Ferrara, S. Heidarkhani, Multiple solutions for a perturbed $p$-Laplacian boundary value problem with impulsive effects, Electron. J. Differ. Eq., 2014(2014), no. 106, 1-14.

[11] J.R. Graef, J. Henderson, A. Ouahab, Impulsive Differential Inclusions, A Fixed Point Approach, De Gruyter Series in Nonlinear Analysis and Applications, Vol. 20, W. De Gruyter, Berlin, 2013.

[12] Y. Jabri, The Mountain Pass Theorem, Variants, Generalizations and some Applications, in: Encyclopedia of Mathematics and its Applications, 95, Cambridge, New York, 2003.

[13] V. Lakshmikantham, D.D. Bainov, P.S. Simeonov, Theory of Impulsive Differential Equations, Series in Modern Applied Mathematics, Vol. 6, World Scientific, Teaneck, NJ, 1989.

[14] E.K. Lee, Y.H. Lee, Multiple positive solutions of singular two point boundary value problems for second order impulsive differential equation, Appl. Math. Comput., 158(2004), 745-759.

[15] X.N. Lin, D.Q. Jiang, Multiple positive solutions of Dirichlet boundary value problems for second order impulsive differential equations, J. Math. Anal. Appl., 321(2006), 501-514.

[16] J.J. Nieto, D. O'Regan, Variational approach to impulsive differential equations, Nonlinear Anal. Real World Appl., 10(2009), 680-690.

[17] J.J. Nieto, R. Rodríguez-López, Boundary value problems for a class of impulsive functional equations, Comput. Math. Appl., 55(2008), 2715-2731.

[18] P.H. Rabinowitz, Minimax Methods in Critical Point Theory with Applications to Differential Equations, CBMS Reg. Conf. Ser. Math. 65, Amer. Mat. Soc., Providence, 1986.

[19] B. Ricceri, A general variational principle and some of its applications, J. Comput. Appl. Math., 113(2000), 401-410.

[20] J. Simon, Regularitè de la solution d'une equation non lineaire dans $R^{N}$, in: Journées d'Analyse Non Linéaire (Proc. Conf., Besançon, 1977), (P. Bénilan, J. Robert, eds.), Springer, BerlinHeidelberg-New York, Lecture Notes in Math., 665(1978), 205-227.

[21] Y. Tian, W. Ge, Variational methods to Sturm-Liouville boundary value problem for impulsive differential equations, Nonlinear Anal., 72(2010), 277-287.

[22] L. Wang, L. Chen, J.J. Nieto, The dynamics of an epidemic model for pest control with impulsive effect, Nonlinear Anal. Real World Appl., 11(2010), 1374-1386.

[23] J. Xiao, J.J. Nieto, Z. Luo, Multiplicity of solutions for nonlinear second order impulsive differential equations with linear derivative dependence via variational methods, Commun. Nonlinear Sci. Numer. Simul., 17(2012), 426-432.

[24] E. Zeidler, Nonlinear Functional Analysis and its Applications, Vol. II, Springer, BerlinHeidelberg-New York, 1990.

[25] D. Zhang, B. Dai, Existence of solutions for nonlinear impulsive differential equations with Dirichlet boundary conditions, Math. Comput. Modelling, 53(2011), 1154-1161.

[26] H. Zhang, Z. Li, Variational approach to impulsive differential equations with periodic boundary conditions, Nonlinear Anal. Real World Appl., 11(2010), 67-78.

[27] Z. Zhan, R. Yuan, Application of variational methods to Dirichlet boundary value problem with impulses, Nonlinear Anal. Real World Appl., 11(2010), 155-162.

Received: October 8, 2015; Accepted: June 7, 2016. 